\title{
Level and Correlates of Self-medication among Adults in a Rural Setting of Mainland Tanzania
}

\author{
M. R. KAZAURA* \\ Department of Epidemiology/Biostatistics, Muhimbili University of Health and Allied Sciences, Dar es Salaam 65015, Tanzania
}

\author{
Kazaura: Self-medication in Tanzania
}

\begin{abstract}
A descriptive cross-sectional study was conducted to estimate the proportion of adults practicing selfmedication in a rural setting of Tanzania. Using a structured interview schedule, we interviewed adults (aged at least 18 years) living in two selected wards. Data analysis involved descriptive statistics and logistic regression analysis. Among 474 study participants, 364 (76.8\%) reported having experienced illnesses during the past three months before the survey. Among these, 236 (64.8\%) reported having practiced self-medication. The main reported reason behind this practice was lack of money to consult a medical doctor. The major reported self-medication drugs include antipyretics $167(58.2 \%)$, analgesics $162(56.4 \%)$ and antimalarials $118(41.1 \%)$. Use of antibiotics was reported by $51(17.8 \%)$ participants. Self-medication was significantly associated with sex, education status and occupation of the respondent. Males had almost twice odds to practice self-medication as compared to females, Adjusted odds ratio was 1.9 (95\% confidence interval, 1.13.4). Also, respondents with incomplete primary education had about four odds to practice self-medication than those without formal education. Although there were few participants reporting use of antibiotics, we recommend health educators to enhance understanding of benefits and possible risks associated with selfmedication. Also, we recommend a study to examine the attitudes associated with self-medication practices.
\end{abstract}

Key words: Pharmacy, practice, rural, self-medication

Traditionally, self-medication (SM) was defined as 'taking of drugs, herbs or home remedies on one's own initiative, or on the advice of another person, without consulting a doctor' ${ }^{[1]}$. However, the World Health Organization (WHO) on one hand, defined SM as the 'use of drugs to treat self-diagnosed disorders or symptoms, or the intermittent or continued use of a prescribed drug for chronic or recurrent disease or symptoms' and on the other hand, indicated that overthe-counter (OTC) medication as the one the buyer diagnoses his/her own illness and buys a specific drug to treat $\mathrm{it}^{[2]}$. SM practices are very common in both developed and developing countries ${ }^{[3,4]}$.

Despite the limited data on self- and OTC medications in Tanzania, the current available data on SM and OTC in Tanzania have focused mainly on malaria and fever-related illnesses ${ }^{[5-7]}$. In all these cases, SM and OTC medications were found to be very common practices among interviewed participants. Among the main reported reasons for the widespread use of SM include rising recognition of self-care, feeling of sympathy toward family members in sickness, limited health services, poverty and ignorance,

*Address for correspondence

E-mail: mrkazaura@muhas.ac.tz

May-June 2017 extensive advertisement of drugs and availability of drugs in establishments other than pharmacy shops ${ }^{[8]}$. Nevertheless, inappropriate use of SM and OTC medications may lead to possible drug resistance and drug toxicity caused by incorrect diagnosis, underdosing and incorrect use of non-prescribed drugs. Other serious risks of using SM inappropriately have been discussed by Ruiz and Worku ${ }^{[9,10]}$.

In this study, data was generated using a quantitative approach from a rural setting of mainland Tanzania to estimate the level of SM with OTC medications, reasons for use and perceived outcomes after the use of such medications. A descriptive-cross-sectional study was conducted in two wards of Pwani Region in mainland Tanzania. These wards are Kibiti and Ikwiri. The ward is an administrative area with several

This is an open access article distributed under the terms of the Creative Commons Attribution-NonCommercial-ShareAlike 3.0 License, which allows others to remix, tweak, and build upon the work non-commercially, as long as the author is credited and the new creations are licensed under the identical terms

Accepted 05 April 2017

Revised 29 December 2016

Received 04 March 2016

Indian J Pharm Sci 2017;79(3):451-457 
hamlets covering approximately 20000 to 30000 people. During the most recent national census, Pwani Region and the two wards had a total population of 1098668 and 27 356, respectively ${ }^{[11]}$. Economically, the people in this region, like in other rural regions of Tanzania, remain extremely poor and are characterized by poor hospital infrastructure including equipment ${ }^{[12]}$. Nevertheless, the community in these two wards relied on one referral public district (Utete) hospital, one private (Mchukwi) hospital, two health centres and several public and private dispensaries for their hospital needs. Although these two wards have 18 (10 in Kibiti and 8 in Ikwiriri) registered pharmacy shops (as per Pharmacy Council of Tanzania Register), people normally get medication beyond theses shops as they actually have freedom to do so.

From the two wards that constitute the study area, an estimated sample size chosen for this study was 492 households. These households were split equally between the two wards. In each ward, five streets were randomly selected. Then, a random sampling was applied to select 50 households. In each of the selected household, one adult (aged at least 18 y) living in this area for at least a year was selected. In case the household had more than one adult, simple random sampling was applied to select one adult.

Data were collected from respondents using structured questions. This interview schedule was administered by medical students who were also trained on the research topic and data collection process. Pre-testing of the data collection instrument was conducted in a similar population. The main variables included participant's age, sex, marital and education status, perceived household income, SM practice, type of drugs selfmedicated, source of advice and outcome of the illness.

Data analysis was performed using SPSS (Version $19)^{[13]}$. Main procedures involved were descriptive statistics (frequencies), logistic regression analysis (both unadjusted and adjusted) with reporting SM being the outcome variable and selected background variables being explanatory variables. The cut-off point for availability of association was P-value $<0.05$ and $95 \%$ confidence interval as a measure of strength.

Prior to data collection, an ethical clearance was requested from Institutional Review Board. Furthermore, we applied for permission to conduct the study from the local government authorities. Privacy and confidentiality were observed throughout the study to make sure participants were comfortable when responding to the questions and no participant was identified by names rather by code numbers necessary during data entry, cleaning and for further processing. Each study participant was informed before the interview that they are free to skip responding to any question and that they can stop the whole interview at any time. Eventually, an oral consent was requested from each participant.

A total of $474(96.3 \%)$ adult women and men out of the original estimated sample size were recruited. Their average age (median) was 30.0 (inter-quartile range was 16) years. The majority were females 364 $(76.8 \%)$ and around $370(57.0 \%)$ of the total subjects had completed at least primary education, $324(68.4 \%)$ were either married or cohabiting but only $26(5.5 \%)$ formally employed and $333(70.3 \%)$ considered their household to be in the lower income bracket. Other characteristics were presented in Table 1.

Among all people interviewed, 364 (76.8\%) mentioned that during the past three months before the survey they felt ill at least once and used some form of modern medications. Of these, during the most recent ailment, only $128(35.2 \%)$ were advised (or received prescriptions) by the qualified medical personnel. Therefore, the rate of SM was $236(64.8 \%, 95 \%$ CI, 59.7-69.7\%). Among those who had SM within the previous three months before the survey, the reported median frequency of use was twice ranging between once and ten times. Individuals who advised ailing respondents to use modern medications are presented in fig. 1. Beyond the medical personnel, the main advisers for SM were self-motivated, 103 (28.3\%) and pharmacy personnel 80 (22.0\%).

The main reported reasons for SM were lack of money especially for medical consultation 170 (59.2\%) and that they thought mild ailments do not require seeking treatment from medical health personnel, 112 (39.0\%). Other reasons included poor quality services at the health facility including long queues 46 (16.0\%), long distances to the health facility $28(9.8 \%)$ and 19 (10.9\%) cited other reasons (fig. 2).

Among the major reported symptoms associated with use of SM included fever 177 (61.7\%), general body or muscular pains 155 (32.7\%) and common cold 90 $(31.4 \%)$. Other reported symptoms were presented in Table 2. Some of the reported categories of medicines used as SM include various antipyretics $167(58.2 \%)$, analgesics 162 (56.4\%), antimalarials 118 (41.1\%) and antibiotics, 51 (17.8\%). Other medications were 


\begin{tabular}{lc}
\hline \multicolumn{1}{c}{ Characteristic } & Number $(\%)$ \\
\hline Sex & $110(23.2)$ \\
Female & $364(76.8)$ \\
Current age (years) & \\
$<30$ & $222(46.8)$ \\
$30-39$ & $125(26.4)$ \\
$40-49$ & $74(15.6)$ \\
$50+$ & $53(11.2)$ \\
Education & \\
No formal education & $150(31.6)$ \\
Primary (incomplete) & $54(11.4)$ \\
Primary (complete) & $214(45.1)$ \\
Secondary and above & $56(11.9)$ \\
Current marital status & \\
Never/not married & $85(17.9)$ \\
Married/cohabiting & $324(68.4)$ \\
Divorced/separated & $36(7.6)$ \\
Widow & $29(6.1)$ \\
Occupation & \\
Formal employment & $26(5.5)$ \\
Not employed & $59(12.4)$ \\
Other* & $389(82.1)$ \\
Perceived income level & \\
High & $3(0.6)$ \\
Average & $138(29.1)$ \\
Low & $333(70.3)$ \\
\hline Houswe, patt &
\end{tabular}

*Housewife, part-time jobs

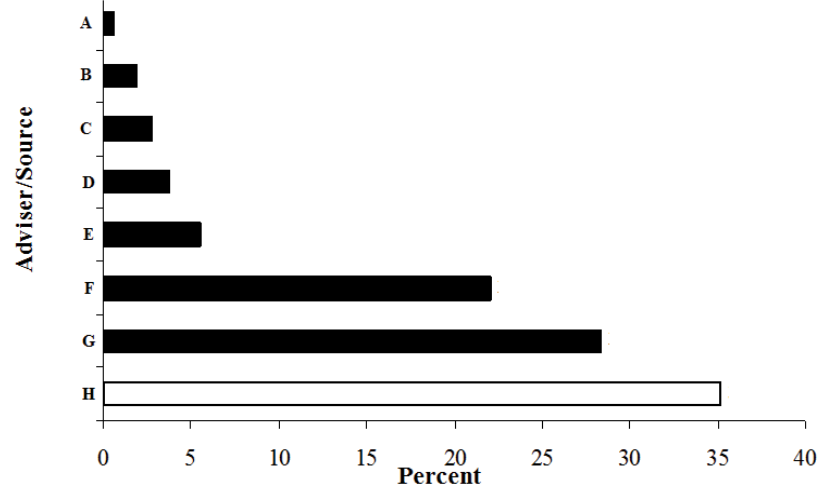

Fig. 1: Proportion of respondents reporting source of medication practices

A: others; B: advertisement; C: leftovers; D: friend; E: family member; F: pharmacy personnel; G: self; H: medical personnel

presented in fig. 3 .

A total of 343 (among the 364 respondents who felt ill during the past three months) reported outcomes of the medications (either given by the medical personnel or otherwise). Reported outcomes were symptoms subsided 178 (51.9\%), disappeared 134 (39.1\%), persisted $27(7.9 \%)$ or worsened $4(1.2 \%)$. Among 312 respondents who reported that symptoms either subsided or completely disappeared, 195 (62.5\%) were advised to get medications by medical personnel as compared to $10(32.3 \%)$ who reported that symptoms persisted or worsened $(\mathrm{P}<0.01)$.

In Table 3 results from the multivariable logistic regression analysis were presented with SM being the outcome variable of interest. Among the hypothesized variables to be associated with dependent variable: sex, education status and occupation were significantly associated with SM practices. For example, males were about twice, a $\mathrm{OR}=1.9(95 \% \mathrm{CI}, 1.1,3.4)$, greater than females to practice SM. Also, the odds of practicing SM were 4.1 (95\% CI, 1.7, 9.8) greater for respondents with incomplete primary education than those without formal education and were twice (95\% CI, 1.2, 3.3) among respondents with completed primary education than those who never went to school.

In the current study, we found high prevalence (about $65 \%$ ) of adults living in a rural area setting of mainland Tanzania practicing SM. Previous studies from subSaharan Africa with different study population and with specific types of morbidities found higher prevalence (over $70 \%$ ) of $\mathrm{SM}^{[14-16]}$. Furthermore, in one rural area of Tanzania, a recent qualitative study suggested SM 


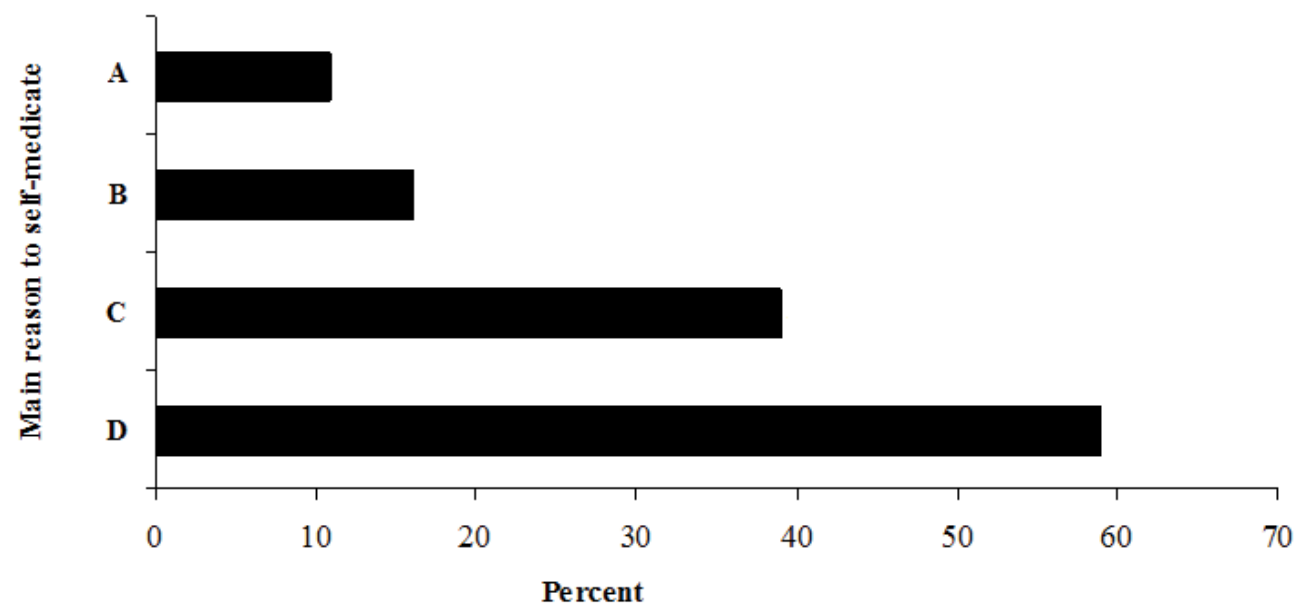

Fig. 2: Main reasons for practicing self-medication of modern medicine A: others; B: long queues; C: mild ailment; D: high treatment costs

\section{TABLE 2: REPORTED MAJOR SYMPTOMS ASSOCIATED WITH SELF-MEDICATION}

\begin{tabular}{lc}
\hline Characteristic & Number (\%) \\
\hline Common cold & $90(31.4)$ \\
Cough & $75(26.1)$ \\
Fever & $117(61.7)$ \\
General pains & $155(54.0)$ \\
Vomiting & $31(10.8)$ \\
Diarrhoea & $25(8.7)$ \\
Skin conditions & $14(4.9)$ \\
Other & $27(15.5)$ \\
\hline
\end{tabular}

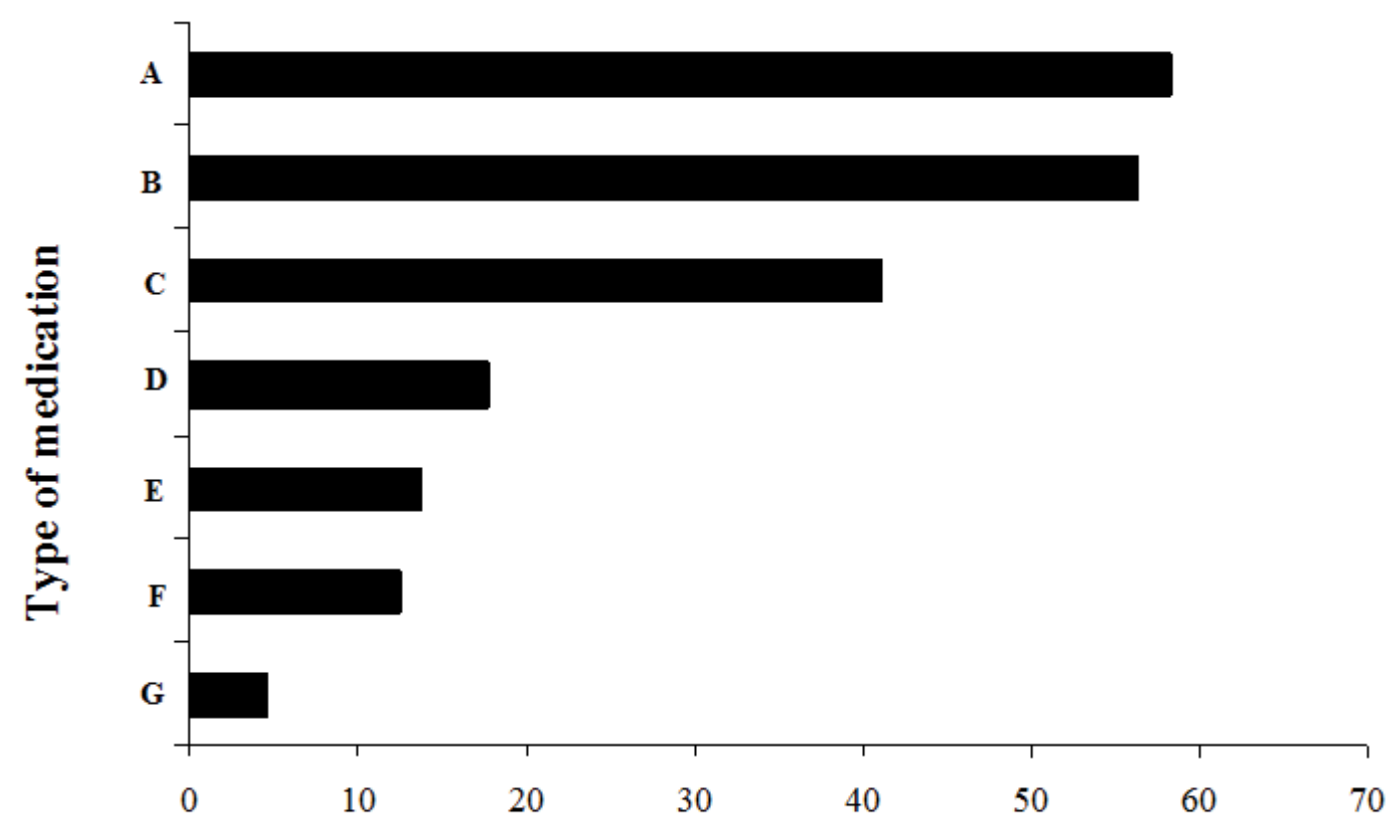

\section{Percent}

Fig. 3: Categories of medicines used for self-medication

A: antipyretics; B: analgesics; C: antimalarials; D: antibiotics; E: antidiarrhoea; F: antiemetics; G: others

practices to be common ${ }^{[5]}$. Therefore, the prevalence of $\mathrm{SM}$ in this study is within the expected limits.
Reasons behind high prevalence of SM were at multiple levels. These levels include individual factors 


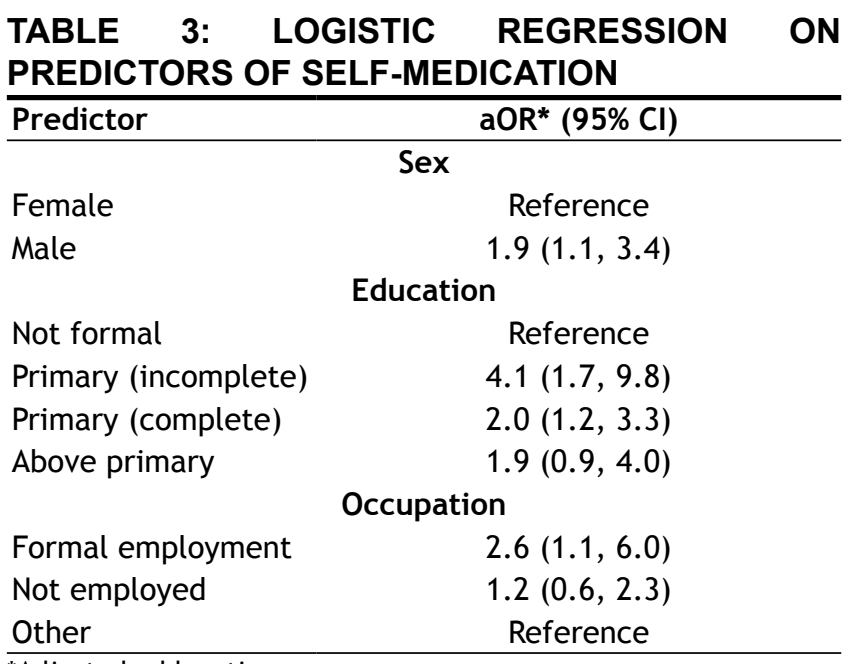

${ }^{*}$ Adjusted odds ratio

such as persistence of the same symptoms frequently leading to patients eventually develop self-diagnosis and self-prescription, social structures such as low socio-economic status, specifically low incomes. Other factors are facility-based such as poor quality provision of health care services. Poor quality of health care services, specifically in East African countries, pose great challenges to health care seekers ${ }^{[17-19]}$.

In this study, the main reported symptoms among people practicing SM included fever and general/ muscular pains. For the past decades, malaria has remained the major cause of hospital admission and death in Tanzania ${ }^{[20]}$. Since fever and body pains are among the main symptoms of malaria, it is very likely that these symptoms would have definitely contributed greatly to people practicing SM. Moreover, in another studies, headache and fever have been reported to be the illnesses or symptoms for practicing $\mathrm{SM}^{[21,22]}$.

Most of respondents reporting SM in this study were advised by pharmacy personnel. Although in many settings, the distance between formal or specialized modern health facilities and health care seekers have been reduced tremendously, drug shops and commercial pharmaceutical stores are wide spread. Besides providing prescribable drugs, they also go beyond by advising clients what drugs to use in case of a particular illness and therefore become major source of advising use of SM drugs ${ }^{[23,24]}$. It is not surprising, the pharmacy personnel to be the main source behind people practicing SM in such an area with few health care facilities and personnel ${ }^{[25]}$.

More than half of the respondents in this study sought or were advised to self-medicate themselves with antipyretics or analgesics. These findings are in line with the reported symptoms (fever and general body or muscular pains) that are associated with these categories of medicines. Use of analgesics and/or antipyretics as the most frequent categories of drugs used for SM have been reported from studies that were conducted in Nigeria and Ethiopia ${ }^{[21,26,27]}$. In poor resource countries like Tanzania, it is expected patients to use antipyretics and analgesics for common illnesses like fever, headache and body pains; when used correctly, they are very effective. However, use of antibiotics for SM though at low rate raises concern because there is a potential risk of creating drug resistance ${ }^{[28]}$.

The association between gender of respondent and SM especially men having elevated odds to SM has been documented previously in a Ugandan study ${ }^{[29]}$. Although there have been studies that suggest more women seeking health care than $\operatorname{men}^{[30]}$, this dominance changes depending on type of morbidity as it is the case for pulmonary tuberculosis ${ }^{[31,32]}$. But in this study, increased odds of SM among males may be linked with men purchasing drugs even for their families. African women especially from rural areas are economically dependent to men. Therefore, in most cases, women would ask their partners or the head of household; who in most cases are men to bring with them drugs for use at household level.

The occupation level is associated with SM. An association of SM with occupation has been reported in a Kano (Nigeria) study ${ }^{[3]}$. The phenomenon of increased odds of SM among respondents with formal employment may be explained by their stable income. Although it has been hypothesized that low income is associated with SM and since formal employment may act to be proxy of a reasonable income, one would expect people with formal employment to have a protective effect when it comes to SM; but in this study, it was opposite. It is possible that the effect of high income to SM works when there are abundant primary and secondary health facilities. This was also explained in the current study by lack of association between perceived level of income and SM.

In this study, there were two potential study limitations. First, because information about SM was self-reported, one would anticipate the possibility of recall bias. We tried to minimize the recall bias by limiting the reporting window to be as short as one month before the survey. Therefore, we think respondents were capable to remember the profile of their medications during this period. 
Second, sampling was done at hamlet level. The hamlet in this setting is a collection of households for the purpose of management and administrative issues. Although one individual was selected in a sampled household, there is a possibility of clustering of these individuals within the ward and within the hamlet. Therefore, there is a possibility that our study participants were not purely independent from one household to the other. Its main effect is the over-flow of sampling errors.

To conclude, the proportion of adults practicing SM was high in a rural setting of mainland Tanzania and this level may also apply in similar areas beyond the targeted area. Sex, education and occupation status were associated with SM practices. Motives for practicing SM are diverse but the main one is lack of user-fees. There is an indication of using antibiotics for SM. This practice raises concern to health educators on the benefits and possible risks associated with $\mathrm{SM}$. On one hand, a rigorous quantitative research is recommended to examine the direction of the association between SM and exposure variables and on the other, a qualitative research to gain understanding on the attitudes surrounding these practices.

\section{Acknowledgements:}

We thank all people who participated in this study by providing valuable information and to all people who assisted at multiple-levels of logistical support including the Muhimbili University of Health and Allied Sciences and the Ward Executive Officers.

\section{Conflict of interest:}

All authors declare no conflict of interests.

\section{Financial support:}

Nil.

\section{REFERENCES}

1. Hernandez-Juyol M, Job-Quesada JR. Dentistry and selfmedication: A current challenge. Med Oral 2002;7:344-7.

2. http://www.who.int/iris/handle/10665/.

3. Van der Geest S, Hardon A. Self-medication in developing countries. J Soc Adm Pharm 1990;7:199-204.

4. Abrahams N, Jewkes R, Mvo Z. Indigenous healing practices and self-medication amongst pregnant women in Cape Town, South Africa. Afr J Reprod Health 2002;6:79-86.

5. Chipwaza B, Mugasa JP, Mayumana I, Amuri M, Makungu C, Gwakisa PS. Self-medication with antimalarials is a common practice in rural communities of Kilosa district in Tanzania despite the reported decline of malaria. Malar J 2014;13:252.
6. Metta E, Haisma H, Kessy F, Hutter I, Bailey A. "We have become doctors for ourselves": motives for malaria self-care among adults in southeastern Tanzania. Malar J 2014;13:249.

7. Mwambete KD, Andrew R. Knowledge on management of fever among mothers of undertens in Dar es Salaam, Tanzania. East Afr J Public Health 2010;7:177-81.

8. Ahmad A, Patel I, Mohanta GP, Balkrishnan R. Evaluation of self-medication practices in rural area of Town Sahaswan at Northern India. Ann Med Health Sci Res 2014;4:S73-S78.

9. Ruiz ME. Risks of self-medication practices. Curr Drug Saf 2010;5:315-23.

10. Worku S. Practice of self-medication in Jimma Town. Ethiop J Health Sci 2004; 17:111-6.

11. http://www.nbs.go.tz/nbs/takwimu/census2012/Migration and_Urbanisation_Monograph.pdf.

12. Kruk ME, Hermosilla S, Larson E, Mbaruku GM. Bypassing primary care clinics for childbirth: a cross-sectional study in the Pwani region, United Republic of Tanzania. Bull World Health Organ 2014;92:246-53.

13. https://www.ibm.com/.

14. Awad A, Eltayeb I, Matowe L, Thalib L. Self-medication with antibiotics and antimalarials in the community of Khartoum State, Sudan. J Pharm Pharm Sci 2005;8:326-31.

15. Donkor ES, Tetteh-Quarcoo PB, Nartey P, Agreman IO. Self-medication practices with antibiotics among tertiary level students in Accra, Ghana: a cross-sectional study. Int J Environ Res Public Health 2012;9:3519-29.

16. Abasiubong F, Bassey EA, Udobang JA, Akinbami OS, Udoh $\mathrm{SB}$, Idung AU. Self-medication: potential risks and hazards among pregnant women in Uyo, Nigeria. Pan Afr Med J 2012;13:15.

17. Chuma J, Gilson L, Molyneux C. Treatment seeking behaviour, cost burdens and coping strategies among rural and urban households in Coastal Kenya: an equity analysis. Tropical Med Int Health 2007;12:673-86.

18. Amone J, Asio S, Cattaneo A, Kweyatulira AK, Macaluso A, Maciocco G, et al. User fees in private non-for-profit hospitals in Uganda: a survey and intervention for equity. Int $\mathrm{J}$ Equity Health 2005;4:6.

19. Kahabuka C, Kvåle G, Moland KM, Hinderaker SG. Why caretakers bypass primary health care facilities for child care - a case from rural Tanzania. BMC Health Serv Res 2011;11:315

20. Maegga BT, Cox J, Malley KD. Malaria in the southern highlands of Tanzania: a review of hospital records. Tanzan Health Res Bull 2005; 7:125-32.

21. Eticha T, Mesfin K. Self-medication practices in Mekelle, Ethiopia. PLoS One 2014;9:e97464.

22. Shaghaghi A, Asadi M, Allahverdipour H. Predictors of selfmedication behavior: a systematic review. Iran J Public Health 2014;43:136-46.

23. Cocks M, Dold A. The role of 'African chemists' in the health care system of the Eastern Cape province of South Africa. Soc Sci Med 2000;51:1505-15.

24. Mouhari-Toure A, Kombaté K, Saka B, Akakpo S, Boukari $\mathrm{OB}$, Pitche $\mathrm{P}$, et al. Self-medication for dermatologic conditions in Lomé, Togo. Med Trop 2010;70:303-4.

25. Munga $M$, Mæstad $O$. Measuring inequalities in the distribution of health workers: the case of Tanzania. Hum Resour Health 2009; 7:4.

26. Obu HA, Chinawa JM, Ubesie AC, Eke CB, Ndu IK. 
Paracetamol use (and/or misuse) in children in Enugu, SouthEast, Nigeria. BMC Pediatr 2012;12:103.

27. Jerez-Roig J, Medeiros LF, Silva VA, Bezerra CL, Cavalcante LA, Piuvezam G, et al. Prevalence of self-medication and associated factors in an elderly population: a systematic review. Drugs Aging 2014;31:883-96.

28. Sapkota AR, Coker ME, Rosenberg GRE, Atkinson NL, Sweet SJ, Sopeju PO, et al. Self-medication with antibiotics for the treatment of menstrual symptoms in Southwest Nigeria: a cross-sectional study. BMC Public Health 2010;10:610.

29. Ocan M, Bwanga F, Bbosa GS, Bagenda D, Waako P, OgwalOkeng J, et al. Patterns and predictors of self-medication in northern Uganda. PLoS One 2014;9:e92323.

30. Bertakis KD, Azari R, Helms LJ, Callahan EJ, Robbins JA.
Gender differences in the utilization of health care services. J Fam Pract 2000;49:147-52.

31. Yimer S, Holm-Hansen C, Yimaldu T, Bjune G. Health care seeking among pulmonary tuberculosis suspects and patients in rural Ethiopia: a community-based study. BMC Public Health 2009;9:454.

32. Onifade DA, Bayer AM, Montoya R, Haro M, Alva J, Franco $\mathrm{J}$, et al. Gender-related factors influencing tuberculosis control in shantytowns: a qualitative study. BMC Public Health 2010;10:381.

33. Lawan UM, Abubakar IS, Jibo AM, Rufai A. Pattern, awareness and perceptions of health hazards associated with self-medication among adult residents of Kano Metropolis, Northwestern Nigeria. Indian J Community Med 2013;38:144-51. 